employees spend much more time exposed to ETS in restaurants than do customers, however, and thus are more likely to suffer adverse health effects. ${ }^{21} \mathrm{~A}$ major review of studies involving 1000 offices, and more than 400 restaurants and 600 homes, found that levels of ETS in restaurants were 1.6 to 2.0 times higher than in other workplaces and 1.5 times higher than in homes with at least one smoker. ${ }^{21}$ Furthermore, epidemiological evidence suggests a $50 \%$ increase in lung cancer risk among food service employees that is at least partly attributable to exposure to ETS in the workplace. ${ }^{21}$

Thus evidence from studies of exposure levels and customer demand suggests that legislation is necessary to protect employees and customers. The role of litigation in increasing the number of smoke-free restaurants or provision of smoke-free areas in restaurants is likely to become more prominent with an increasing number of successful cases providing compensation for workplace exposure to secondhand smoke. The case of Liesel Scholem in 1992 in Australia has been seen as a catalyst for accelerating the introduction of smoke-free policies in the workplace in NSW. ${ }^{22}$ A survey of workplaces in Sydney, undertaken about eight weeks after the Scholem decision, showed that $89 \%$ of companies reported being aware of recent legal developments and more than half the 359 companies interviewed could name the Scholem case.$^{23}$ Of those who were aware of legal developments, $42 \%$ reported that the decision had had an impact on their smoke-free policy. Such cases have the potential to significantly increase the pace of change in this important area of exposure to ETS.

Evidence is also accumulating to debunk concerns about the impact of smoking legislation on restaurant sales, a major barrier held up in the past by restaurateurs, or the tobacco industry under the guise of restaurant organisations, to slow progress towards smoking bans in restaurants. Samuels and Glantz document the unsubstantiated claims by restaurant organisations of substantial reductions in income following the introduction of smoking bans. ${ }^{10} \mathrm{~A}$ recent analysis, however, of centralised restaurant sales data in California from 1986 to 1993 across 15 cities that introduced legislation and 15 cities selected as controls, showed no effect on the fraction of total retail sales that went to restaurants or on the ratio of restaurant sales in legislation versus matched control communities. ${ }^{24}$

Restaurants are the most frequented public venue in the $\mathrm{US}^{25}$ and the highest source of exposure to ETS. ${ }^{21}$ Despite a favourable trend over time in the number of states with restrictions on smoking in restaurants, further action is needed to strengthen existing legislation, to disseminate legislative change more widely, and to develop effective implementation and enforcement strategies to ensure protection of both employees and customers.

MARGOT J SCHOFIELD
Discipline of Behavioural Science in Relation to Medicine,

Faculty of Medicine and Health Sciences,

University of Newcastle,

Locked Bag No 10,

Wallsend NSW 2287, Australia

1 US Department of Health and Human Services. The health consequences of involuntary smoking. A report of the Surgeon General, 1986. Rockville, Maryland: Public Health Service, Centers for Disease Control, 1986. (DHHS Publication No (CDC) 87-8398.)

2 US Environmental Protection Agency. Respiratory health effects of passive smoking: lung cancer and other disorders. Washington, DC: Office of Health and Environmental Assessment, 1992. Publication (EPA/600/6$90 / 006 \mathrm{~F})$.

3 Glantz SA, Parmley WW. Passive smoking and heart disease: epidemiology, physiology, and biochemistry. Circulation 1991; 83:1-12.

4 US Centers for Disease Control. Passive smoking: Beliefs, attitudes and exposures, United States 1986. MMWR 1986; 37: 239-41.

5 Rigotti NA. Trends in the adoption of smoking restrictions in public places and worksites. NY State $\mathcal{F}$ Med 1989; 89:19-26.

6 Chapman S. Australian court rules that passive smoking causes lung cancer, asthma attacks and respiratory disease. BMF 1991; 302: 943-5.

Waranch HR, Wohlgemuth WK, Hantula DA, Gorayeb R, Stillman FA. The effects of a hospital smoking ban on employee smoking behaviour and participation in different types of smoking cessation programmes. Tobacco Control 1993; 2: 120-6.

8 Borland R, Owen N, Hill D, Chapman S. Staff members' acceptance of the introduction of workplace smoking bans in the Australian public service. Med $\mathcal{F}$ A A st $1989 ; 151$ : 525-8.

9 Hill D. Public opinion about smoking in restaurants and at work. Med $\mathcal{F}$ Aust 1986; 145: 657-8.

10 Samuels B, Glantz SA. The politics of local tobacco control. $\mathcal{F} A M A 1991$; 266: $2110-17$.

11 Orth $\mathrm{K}$. Self-regulation - not legislation: to the restaurateur. Letter to members. Crows Nest, NSW: National Restaurant \& Catering Association of Australia, 1990 .

12 Schofield MJ, Considine R, Boyle CA, Sanson-Fisher R. Smoking control in restaurants: the effectiveness of self-regulation in Australia $A m \mathcal{F}$ Public Health 1993; 83: 1984-8.

13 US Department of Health and Human Services. Environmental tobacco smoke in the workplace: lung cancer and other health effects. Cincinnati, Ohio: National Institute for Occupational Safety and Health, 1991. (DHHS Publication No (NIOSH) 91-108.)

14 Andrews B. Patron choice of non-smoking or smoking areas at a large restaurant in rural Australia: a four-year study. Tobacco Control 1995; 4 : 129-31.

15 Borland R, Mullins R. How bothered are people by environmental tobacco smoke? Med F Aust 1994; $160: 585$.

16 Schofield MJ, Edwards K. Community attitudes towards bans on smoking in licensed premises. Aust $\mathcal{F}$ Public Health, in press.

17 Nordstrom DL, DeStefano. Evaluation of Wisconsin legislation on smoking in restaurants. Tobacco Control 1995; 4:125-8.

18 Pertschuk M, Shopland DR, eds. Major local smoking ordinances in the United States. Washington, DC: US Department of Health and Human Services, 1989.

19 Chapman S: Reducing teenage access to cigarettes in Australia: time to act Med $\mathcal{F}$ Aust 1993; 158: 219-20.

20 Lambert WE, Samet JM, Spengler JD. Environmental tobacco smoke concentrations in no-smoking and smoking sections of restaurants. $A m \mathcal{F}$ Public Health 1993; 83: 1339-41.

21 Siegel $M$. Involuntary smoking in the restaurant workplace: a review of employee exposure and health effects. $\mathcal{F A M A} 1993 ; 270: 490-3$.

22 Gottlieb M. Australian passive smoker successfully brings suit against employer. World Smoking Health 1992; 17: 13-15.

23 Palin M, Young M. The impact of smoking litigation on Australian workplaces. Tobacco Control $1994 ; 3: 78-9$.

24 Glantz SA, Smith LRA. The effect of ordinances requiring smoke-free restaurants on restaurant sales. Am f Public Health 1994; 84: 1081-5.

25 US Department of Health and Human Services. Preventing tobacco use among young people. A report of the Surgeon General. Atlanta, Georgia: Public Health Service, Centers for Disease Control and Prevention, Office on Smoking and Health, 1994 (US Government Printing Office No S/N 017-001-00491-0.)

\title{
Signal and noise in minimal interventions for smoking cessation
}

In this issue of Tobacco Control, Slama et al ${ }^{1}$ demonstrate the efficacy and potential public health benefit of a nearly effortless smoking cessation intervention delivered by French general practitioners. Although Slama et al acknowledge the methodological limitations of their trial, it is important to note that their data dovetail with an international body of findings that strongly attests to the efficacy of minimal clinical interventions with patients who smoke. ${ }^{2-4}$ The take-away message, the "signal" of the trial by Slama et al, therefore, is the imperative that physicians and clinics must intervene with all smokers, because even brief advice to quit will have a positive, cumulative impact.

The paper by Slama et al is valuable in another way; it illustrates how researchers in smoking cessation must struggle with methodological challenges, or "noise", germane to the evaluation of minimal clinical interventions. In essence, Slama et al and other researchers have detected and communicated the value of minimal 
interventions, despite the interference of noisome method-

$\equiv$. ological impediments. Because they have the potential to mask or distort the value of minimal interventions, further progress in this area may depend upon the identification and avoidance of such obstacles.

$s$

$x$

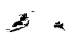

5

\section{On clinical trials (and tribulations)}

Because of the small absolute success rates associated with minimal smoking cessation interventions, trials evaluating them require large numbers of patients and physicians to have sufficient power to detect their presumed impact. The logistic problems produced by the modest effects of minimal interventions virtually guarantee that trials investigating such interventions will be more challenging to design and conduct than are trials of more intensive interventions. These special challenges may manifest themselves in myriad ways, depending upon the details of individual interventions and trial designs. In this section, we consider three interpretive problems discussed by Slama and colleagues that are likely to be encountered in any investigation of minimal clinical interventions: deception assessment; evaluation reactivity; and physician effects.

Perhaps the most common barrier to interpreting the results of minimal clinical interventions is uncertainty about the rate at which patients attempt to deceive outcome assessors. ${ }^{5}$ Although epidemiological assessments of selfreported smoking prevalence have been shown to be reasonably reliable, ${ }^{6,7}$ clinical trials of smoking cessation usually note differences between self-reported and biochemically confirmed abstinence rates, mandating the latter as the standard in evaluating intensive interventions.

The biochemical assays often used to confirm patients' self-reports in trials of intensive studies are not easily integrated into minimal intervention trials; such assessments are time-consuming and expensive (even if they were only to be performed on a randomly selected subsample of patients). Moreover, it may be that many patients in minimal intervention trials fail to comply with biochemical ascertainment. As opposed to patients in trials investigating intensive cessation treatments, patients in minimal intervention trials often do not seek out treatment, and thus may be less motivated to cooperate with research activities. Moroever, patients in minimal intervention trials typically do not receive anything of obvious economic value - for example, intensive counselling or free medication - and this may further decrease their willingness to comply with biochemical verification.

Although we acknowledge that these difficulties lead some investigators to eschew biochemical validation, interpreting the results of minimal intervention trials remains problematic when information about deception rates is lacking. For example, Slama et al conjecture that the differences in smoking rates between the intervention and control groups may reflect the special access that physicians have to information about smoking. Although this may be true, it is also plausible that the difference in outcome between treatment and control groups is due, at least in part, to greater deception among patients undergoing intervention. For example, some of these patients may have perceived the connection between their physician's advice to quit smoking and the survey, and this may have caused them to falsely report cessation.

Because interpretation of trial results can hinge on deception rates, investigators should attempt to obtain the best estimates of deception possible. For instance, a good strategy would be to administer biochemical assessments to random samples of patients from each group, making sure that the sample is collected shortly after the self- report is obtained. It may be necessary to offer financial incentives to promote cooperation. Although this procedure $i$ sime-consuming and expensive, it may be a sine qua non for trust in our research findings. Where it not feasible to recruit a large random sample of study patients for biochemical verification, other strategies might be profitably employed.

Evaluation reactivity is a second major concern in minimal intervention trials. Informed consent procedures and the collection of smoking-related data may cause changes in smoking behaviour that would not have otherwise occurred. Reactivity effects are well-documented in smoking cessation research, as well as in many other areas of behaviour change..$^{89}$ As Slama et al point out, reactivity effects may occur in either the treatment or control group. In the Slama et al trial, control patients were simply asked whether they would participate in a health survey at their clinic visit, whereas patients in the intervention group were asked about their smoking and about their willingness to participate in the survey. It is possible that patients in the intervention group made the connection between the intervention and the survey. Their suspicion that their smoking status would be monitored may have motivated more of them to quit than the intervention alone would have. Alternatively, it is possible that only those smokers who desired to quit smoking consented to be surveyed. Thus, attributing group differences to the intervention alone may be inappropriate.

Reactivity effects are likely to be small, and probably can be safely ignored in tests of more intensive interventions. In minimal clinical interventions, however, reactivity effects may be large relative to the intervention effect. Unfortunately, owing to their very nature, the magnitude of reactivity can be difficult to ascertain. Nonetheless, it is often possible to design conditions that have the potential to rule out at least a portion of evaluation-based barriers to interpreting trial results. ${ }^{4}$ For example, future studies modelled after the trial by Slama $e t$ al might incorporate a condition in which patients are asked whether they would be willing to participate in a survey about smoking but are not told to quit by their physician.

The physicians who actually deliver the interventions are a third potential source of bias in the evaluation of minimal interventions. In most cases, study physicians are volunteers who receive neither credit nor payment for their participation. This population of volunteer physicians is thus likely to be much more committed to tobacco control efforts than the average physician. ${ }^{10}$ If this is the case, it raises questions that may complicate the interpretation of trial results. For example, can these physicians be trusted to adhere to the trial protocol when it conflicts with their values, such as when it calls for them to withhold intervention from smokers randomised to the control group? Non-compliance with randomisation might be expected to shrink the observed impact of the intervention. Alternatively, it may be the case that volunteer physicians are more skilled at delivering smoking cessation interventions than non-volunteer physicians, tending to inflate the estimate of efficacy of more generalised implementation.

Slama and colleagues were able to check whether study physicians adhered to patient assignment criteria by examining whether the randomisation sheets the physicians sent to the study centre reflected the appropriate ratio of intervention and control patients. Future research in this area should incorporate design features such as this, which allow for assessment of physician behaviour. For example, compliance with the trial protocol might be assessed by audiotaping samples of each physician's contact with patients who smoke. Where possible, the 
Approximate number of new ex-smokers per year potentially produced by the widespread application of minimal smoking cessation intervention in selected countries

\begin{tabular}{|c|c|c|c|c|}
\hline Country & $\begin{array}{c}\text { Approximate adult } \\
\text { population }{ }^{\star} \text { (millions) }\end{array}$ & $\begin{array}{l}\text { Prevalence of smokers } \\
\text { among adults }(\%) \dagger\end{array}$ & $\begin{array}{l}\text { Number of smokers } \\
\quad \text { (millions) }\end{array}$ & $\begin{array}{c}\text { Number of new ex-smokers } \\
\text { per year } \ddagger\end{array}$ \\
\hline $\begin{array}{l}\text { Belgium } \\
\text { Denmark } \\
\text { France } \\
\text { Germany } \\
\text { Greece } \\
\text { Ireland } \\
\text { Italy } \\
\text { The Netherlands } \\
\text { Portugal } \\
\text { Spain } \\
\text { UK } \\
\text { USA }\end{array}$ & $\begin{array}{r}7 \\
4 \\
40 \\
56 \\
7 \\
2 \\
39 \\
11 \\
6 \\
27 \\
40 \\
184\end{array}$ & $\begin{array}{l}36 \\
46 \\
38 \\
36 \\
43 \\
33 \\
33 \\
44 \\
33 \\
41 \\
37 \\
25\end{array}$ & $\begin{array}{r}2.5 \\
1.8 \\
15.2 \\
20.1 \\
3.0 \\
0.6 \\
12.8 \\
4.8 \\
1.9 \\
11.1 \\
14.8 \\
46.0\end{array}$ & $\begin{array}{r}49000 \\
35280 \\
297920 \\
393960 \\
58800 \\
11760 \\
250880 \\
94080 \\
37240 \\
217560 \\
290080 \\
901600\end{array}$ \\
\hline
\end{tabular}

$\star$ Adult population estimates were computed by multiplying total populations listed in reference 15 by 0.7 . This conversion factor was used because it pro-

duces an accurate estimate of the number of adult smokers in the US.

+ Smoking prevalence data are drawn from references 16 and 17.

¥ Calculations assume that $70 \%$ of adult smokers visit a physician annually ${ }^{14}$ and that physician intervention results in a $2.8 \%$ long-term success rate. ${ }^{1}$

extent to which trial results can be generalised to general medical practice should also be assessed. For instance, study physicians might be asked to rate their commitment to tobacco control activities and these ratings could be compared with the ratings of a subsample of non-volunteer physicians. Abstinence rates might also be calculated for the patients of individual study physicians, allowing the relations between physician characteristics and clinical success to be examined.

To paraphrase Slama et al, individual trials of minimal interventions generally represent the first step in a multistep process. Replication, refinement, and extension are important next steps.

\section{Research is nice, but action is imperative}

Although no minimal clinical intervention trial is completely unimpeachable, the cumulative weight of imperfect evidence must count for something. More than 20 years of research into minimal interventions has consistently indicated that simple interventions delivered during the course of routine medical visits are capable of modifying smoking behaviour. Although questions of academic interest clearly remain to be answered by minimal intervention trials, it is equally clear that the data amassed to date require physicians and clinics to identify and intervene with their patients who smoke.

From an implementation point of view, the results of Slama et al highlight the importance of institutionalising smoking status assessment and intervention across a whole clinic rather than focusing on the treating physician as the sole locus of intervention. ${ }^{11}$ One institutional change proposed to address this issue is to expand the vital signs to include smoking status so that all patients are asked about their tobacco use at every clinic visit, usually by a member of staff such as a medical assistant. ${ }^{12}$ At the University of Wisconsin, this simple, low-cost change has resulting in more than $80 \%$ of patients reporting that they were asked during their visit about smoking. It has also doubled the rate at which patients report that they were advised on and assisted with quitting. ${ }^{13}$

Enormous public health benefits would accrue if all clinics ensured that smokers were identified and all physicians routinely advised against smoking. Because smokers are a "captive audience", frequently visiting the clinic setting, ${ }^{14}$ physicians are uniquely poised to decrease the prevalence of smoking, despite the relatively low success rates associated with minimal interventions. For example, if one assumes the widescale implementation of a minimal intervention that yields a long-term smoking cessation rate of $2.8 \%$ (that reported by Slama et al), the overall impact on national smoking rates would be very meaningful. The table provides estimates of the potential impact of minimal intervention if such interventions were institutionalised across various developed countries. These estimates, along with the results reported by Slama et al in this issue, emphasise that minimal smoking cessation interventions are a powerful and underused public health tool in the overall battle against tobacco addiction. MICHAEL C FIORE THOMAS M PIASECKI TIMOTHY B BAKER

Center for Tobacco Research and Intervention

University of Wisconsin Medical School

7275 Medical Sciences Center

1300 University Avenue

Madison, Wisconsin 53706-1532, USA

1 Slama K, Karentsy S, Hirsh A. The effectiveness of minimal intervention by general practitioners with their smoking patients: A randomised controlled trial in France. Tobacco Control 1995; 4:00-00

2 Glynn TJ. Relative effectiveness of physician-initiated smoking cessation programs. Cancer Bull 1988; 40: 359-64.

programs. Cancer Bull 1988; 40: $359-64$.
3 Schwartz JL. Review and evaluation of smoking cessation methods: the United States and Canada, 1978-1985. Public Health Service, National Cancer Institute, 1987. (NIH Publication No 87-2940.)

4 Russell MAH, Wilson C, Tailor C, Baker C. Effect of general practitioners' advice against smoking. $B M \mathcal{F} 1979 ; 2: 231-5$.

5 Warner KE. Possible increases in the underreporting of cigarette consumption. F Am Stat Assoc 1978; 73: 314-18.

6 Pojer R, Whitfield JB, Poulos V, Eckhardt IF, Richmond R, Henseley WJ Carboxyhemoglobin, cotinine, and thiocyanate assay compared for distinguishing smokers from non-smokers. Clin Chem $1984 ; 30: 1377-80$ 7 Pierce JP, Dwyer T, Digiusto E, et al. Quit for Life Steering Committee. Cotinine validation of self-reported smoking in commercially run community surveys. $\mathcal{F}$ Chron Dis 1987; 40:689-95.

$8 \mathrm{McFall}$ RM, Hammen CL. Motivation, structure, and self-monitoring: The role of nonspecific factors in smoking reduction. $\mathcal{f}$ Consult Clin The role of nonspecific
Psychol $1971 ; 37: 80-6$.

9 Maletsky BM. Behavior recording as a treatment: A brief note. Behav Ther 1974; 5 . 107-12.

10 Kottke TE, Solberg LI, Brekke ML, Conn SA, Maxwell PM, Brekke MJ. A controlled trial to integrate smoking cessation advice into primary care practice: Doctors Helping Smokers, Round III. $\mathcal{F}$ Fam Pract 1992; 34 701-8.

11 Schwartz JS, Cohen SJ. Changing physician behavior. Primary care research: an agenda for the 90s. Bethesda, Maryland: Public Health Service, National Institutes of Health, 1990; 45-53. (DHHS Publication No (PHS) 90-3460.)

12 Fiore MC. The new vital sign: Assessing and documenting smoking status. fAMA 1991; 266 : 3183-4.

13 Fiore MC, Jorenby DE, Sckensky AE, Smith SS, Bauer RR, Baker TB. Smoking status as the new vital sign: Impact on assessment and Smoking status as the new vital sign: Impact on assessment and
intervention with patients who smoke. Mayo Clin Proc 1995; 70:209-13.

14 US Centers for Diseases Control and Prevention. Physician and other health-care professional counseling of smokers to quit - United States, 1991. MMWR 1993; 42: 854-7.

15 Rand-McNally World Facts and Maps. Rand-McNally \& Co., 1995.

16 Hill C. Trends in tobacco use in Europe. $\mathcal{F}$ Natl Cancer Inst Monogr 1992 12: $21-4$.

17 US Centers for Disease Control and Prevention. Cigarette smoking among adults - United States, 1992, and changes in the definition of curren cigarette smoking. $M M W R$ 1994; 43 : 342-6. 